\title{
LA GENEALOGÍA DE LOS REGLAMENTOS ESCOLARES EN MÉXICO: ANÁLISIS DE LA OBRA DE RAFAEL RAMÍREZ
}

\author{
Ana Cecilia Valencia Aguirre ${ }^{1}$ \\ Universidad de Guadalajara - México \\ anaceciliava@yahoo.com.mx
}

Recepción: 13/03/2011

Evaluación: 25/04/2011

Aceptación: 22/06/2011

Artículo de Revisión

\section{RESUMEN}

Este trabajo es resultado de un análisis cuya pregunta central es ¿Cuál es la genealogía de los reglamentos en las escuelas de educación primaria en México? el objetivo es analizar la obra de Rafael Ramírez, a través de la literatura formativa de los profesores, considerada un elemento fundacional de los mandatos institucionales de la escuela primaria, ya que genera un discurso que instituye la normatividad en la escuela básica mexicana. El método utilizado es el análisis crítico del discurso de Van Dijk, los actos de habla de Searle y la perspectiva de las metáforas de la vida cotidiana de Lakoff. La hipótesis que orienta la indagación plantea que los primeros pasos de la institucionalización del control escolar estuvieron atravesados por el discurso cristiano-católico expresado en diversos interdiscursos de la época y fundamentalmente en los reglamentos escolares que comenzaron a aparecer como parte de la literatura formativa de los profesores de escuelas primarias. Dicho análisis permite concluir que esta literatura refleja gran parte del imaginario de los profesores de escuelas públicas, ya que expresa un nacionalismo

\footnotetext{
${ }^{1}$ Doctora en Educación. Investigadora-Docente del departamento de Filosofía de la Universidad de Guadalajara. Coordinadora de la Maestría en Educación de la Universidad Pedagógica Nacional Unidad Guadalajara, Jalisco. México.
} 
basado en el imaginario de la familia nuclear cristiana, elemento clave que configuró una de las imágenes más vivas en la conformación del estado mexicano posrevolucionario.

Palabras clave: Revista Historia de la Educación Latinoamericana, reglamento, discurso, poder pastoral, familia cristiana, nacionalismo.

\title{
THE GENEALOGY OF THE SCHOOL REGULATIONS IN MEXICO: ANALYSIS OF THE WORK GIVES BY RAFAEL RAMÍREZ
}

\author{
Ana Cecilia Valencia Aguirre \\ Universidad de Guadalajara-México \\ anaceciliava@yahoo.com.mx
}

\begin{abstract}
This work is a result of an analysis and the main question what is the genealogy of the regulations in the schools of primary education in Mexico? This aims at analyzing the work of Rafael Ramirez, across the formative literature of the teachers, considered as a crucial element of the institutional regulations of the primary school, since it generates a speech that the normativity institutes in the basic Mexican school. The used method is the critical analysis of the speech of Van Dijk, the acts of Searle's speeches and the perspective of the metaphors of Layoff's daily life. The hypothesis that orientates the investigation raises that the first steps of the institutionalization of the school control were crossed by the Christian - Catholic speech expressed in diverse inter-speeches of that epoch and fundamentally in the school regulations that began to appear as part of the formative literature of the teachers of primary schools. The above mentioned analysis allows to conclude that this literature reflects great report of the imaginary one, the teachers of public schools, since expresses a nationalism based on the imaginary one of the nuclear Christian family, key element that it formed one of the most alive images in the conformation of the Mexican state after the revolution.
\end{abstract}

Key words: Journal of Latin American Education History regulation, regulations, discourse, pastoral power, Christian family, nationalism. 


\title{
A GENEALOGIA DOS REGULAMENTOS ESCOLARES NO MÉXICO: ANÁLISE DA OBRA DE RAFAEL RAMÍREZ
}

\author{
Ana Cecilia Valencia Aguirre \\ Universidade de Guadalajara- México \\ anaceciliava@yahoo.com.mx
}

\section{RESUMO}

Este trabalho é resultado de uma análise cuja pergunta central é: Qual é a genealogia dos regulamentos nas escolar de educação primária no México? Sem dúvida alguma, o texto de Rafael Ramírez, escrito em 1944 e que recorre a suas experiências de pedagogia comparada nas escolas estadunidenses e mexicanas, é considerado uma obra fundante dos mandados institucionais da escola primária, já que constitui um discurso que institui a normatividade na escola básica mexicana. $\mathrm{O}$ método utilizado é a Análise Crítica do Discurso de Van Dijk, os atos de fala de Searle e a perspectiva das metáforas da vida cotidiana de Lakoff. Com essa metodologia se mostra que o discurso implícito neste regulamento escolar do começo do século XX expressa um afã nacionalista baseado na figura da família nuclear cristã, elemento chave que configurou uma das imagens mais vivas na conformação do estado mexicano pós-revolucionário.

Palavras - chave: Revista História da Educação Latino-americana, regulamento, discurso, poder pastoral, família cristã, nacionalismo. 


\section{INTRODUCCIÓN}

El presente trabajo es el resultado de un análisis, que a su vez constituye parte de un trabajo de investigación, cuya pregunta central es ¿Cuál es la genealogía de las reglamentaciones en las escuelas de educación primaria en México? En este sentido, la noción de genealogía no implica la visión lineal del progreso; si bien intenta ir al origen, pero no lo hace para justificar el desarrollo de una perspectiva sino para rastrear rupturas y discontinuidades en el propio devenir histórico. La mirada genealógica permite ubicar el análisis en una temporalidad sin acotarla a un período específico ni con criterios de exhaustividad, su intención está motivada por las configuraciones del objeto de estudio, su despliegue en el tiempo y en el espacio, siguiendo su trayecto histórico para comprender los procesos de configuración, ruptura y continuidad.

Por otra parte, el concepto de discurso es un referente obligado en este trabajo, que se define como un dispositivo dentro de un sistema estratégico en el que el poder está implicado y gracias al cual funciona. Para Foucault ${ }^{2}$ el poder es algo que opera $a_{4}$ través del discurso, un dispositivo estratégico ${ }^{3}$ de relaciones de poder, una serie de elementos que funcionan dentro del mecanismo general de éste, en este contexto el discurso no es una estructura sino una serie de acontecimientos que generan dominios de acción.

El análisis se centra en un manual escrito para la formación docente se editado en 1944, pero que recoge las experiencias del profesor Rafael Ramírez en escuelas rurales norteamericanas y mexicanas de 1920 a 1940. Por este tipo de documentos sabemos que el estilo para establecer lo que he llamado las funciones del supervisor y directivos escolares se fundó en los llamados manuales, que fueron escritos de carácter práctico y prescriptivo.

Mi tesis central es que los primeros pasos de la institucionalización del control escolar estuvieron atravesados por el discurso cristianocatólico expresado en la perspectiva de José Vasconcelos, primer

\footnotetext{
${ }_{3}^{2}$ FOUCAULT, M. (2001): Tecnologías del yo. Barcelona, Paidós - ICE-UAB, p. 34.

${ }^{3} \mathrm{La}$ noción de estratégico utilizada en este trabajo refiere a un discurso que genera y/o permite cierto radio de acción.

La noción de poder, de acuerdo a Foucault, no refiere a la prohibición, dominación o sujeción sino a la producción, a la acción la cual se controla a través de dispositivos disciplinarios.
} 
secretario de educación en 1924, cuyo eje estructurante fue el modelo de la familia nuclear de clase media en la constitución del imaginario de la función escolar. Así, en los reglamentos para escuelas se asumía que dirigir es controlar, controlar es influir positivamente en la comunidad escolar. La figura del control se encarnaba en la imagen del maestro, visto como un padre de familia, y su tarea fundamental es ser guía orientadora para que la comunidad avance y progrese. Para mostrar estos referentes utilizaré el desmontaje del discurso y la herramienta del análisis crítico, los actos de babla y la concepción de metáfora como elemento de la configuración de la vida cotidiana. Una vez aclarados los alcances del trabajo y las acotaciones metodológicas, mostraré los resultados del análisis.

\section{Organizaçión y administración de escuelas rurales: un texto formativo}

Este es un texto formativo-didáctico, su estilo influyó en las escuelas formadoras de docentes hasta en los años 70 del siglo XX. Es considerado un manual de operación para la organización de las escuelas primarias rurales, su propio autor lo considera una "herramienta práctica". Algunas de las propuestas expuestas en este libro fueron utilizadas como material de enseñanza en las normales rurales. Sin embargo, el texto sigue siendo interesante, porque Ramírez es quien instituye la normatividad escolar a través de estos manuales y crea el mandato que se articula al imaginario de dirigir y controlar una escuela. De ahí que la estructura de este tipo de textos fueron la impronta de los manuales de funciones, que constituían un género de documentos con reglas prácticas escritas en tono moral $:$ si haces esto, por tanto obtendrás

\footnotetext{
${ }^{5}$ Lo imaginario al ser un desplazamiento constituye una metonimia de sentido donde a unos símbolos, que ya tienen algunos significados les atribuimos otras significaciones, o bien les reasignamos sentidos nuevos. Por ello un imaginario no es algo atemporal sino dinámico, ya que adquiere nuevos sentidos de acuerdo a las prácticas sociales de un colectivo.

La noción de desmontaje no es una fragmentación de la unidad, vista como totalidad compleja, sino una revelación de sus unidades de sentido las cuales guardan relación con la estructura.

Es el título de una obra de Rafael Ramírez, padre fundacional de la supervisión escolar. Publicado en 1963, edición del Instituto Federal de Capacitación del Magisterio, creado el 26 de diciembre de 1944. Ésta fue la primera institución en México y América Latina que capacitaba a distancia. Sus textos, el presente era uno de ellos, estaban destinados a que el profesor de manera autodidacta los leyera, pues las condiciones de su trabajo no le permitían recibir una instrucción convencional y escolarizada. Periódicamente se reunía el profesorado en un centro de capacitación para ser evaluado o bien recibir apoyo y asesoría. Así se capacitó a cientos de maestros en México, quienes participaron en la llamada cruzada vasconcelista de la educación nacionalista.

Esto es, bajo la estructura de un juicio hipotético deductivo: Sin obras conforme a "A", por lo tanto, las consecuencias de tus acto te darán "B"
} 
aquello, la estructura argumentativa es si actúas con base en " $a$ ", por tanto obtendrás " $b$ ". Este tipo de texto era común en la época, ya que los principios religiosos y morales estaban inscritas en recomendaciones en forma de manual para dar visibilidad a un hombre educado y formado en los preceptos morales de la época (v.gr. el manual de Carreño ${ }^{10} \mathrm{O}$ el catecismo de Ripalda). Estos textos, en general, tienen un carácter práctico al ser instructivos, recurren a uno de los imaginarios más importantes de la constitución de la tríada del magisterio: la autoridad bajo la imagen del padre o madre, la trivialización del poder al trasladarlo de su dimensión burocrática a la escena doméstica y a la justificación del control en aras de una salud y conversión espiritual: el estar educado. Dicha tríada, autoridad-poder-control, está revestida de la alegoría del servicio, esto es, aparecen en el discurso en forma eufemizada .

La obra comienza con un diagnóstico de la situación de las comunidades rurales e indígenas mexicanas en la década de los treinta, cuyo título es: "México es un país eminentemente rural" . De esta condición Ramírez desprende su atraso, desventaja, ignorancia y pobreza, por tanto, justifica que la educación incida en lo económico, y tenga como tarea prioritaria integrar a la gran masa de población campesina e indígena a un proyecto nacional (cruzada nacionalista) que inició en 1921, recién creada la Secretaría de Educación Pública, siendo su primer secretario José Vasconcelos , quien ya había planteado la necesidad de entender la educación como "una actividad evangelizadora que se efectúa a través de las misiones rurales que predican literalmente el alfabeto y despiertan una efectiva, así sea mínima, conciencia cultural" ". Se puede afirmar que las condiciones de circulación muestran la concordancia entre tres factores:

9 siendo "a" un acto que se desprende en una representación prototípica y a la vez modélica y "b" la consecuencia práctica de la actuación.

Es un manual de urbanidad y buenas costumbres (1853), en el cual se encuentran las principales reglas de civilidad y etiqueta que deben observarse en las diversas situaciones sociales, precedido de un breve tratado sobre los deberes morales del hombre, es un texto clásico en Latinoamérica sobre etiqueta y buenas maneras escrito por Manuel Antonio Carreño.

Se utiliza este término en el sentido de una ocultación que suaviza y oculta de manera tersa una situación o fenómeno.

RAMÍREZ, R. (1944): Organización y administración de Escuelas rurales. México D. F. SEP, Instituto Federal de Capacitación del Magisterio, Biblioteca Pedagógica de Perfeccionamiento Profesional

Vasconcelos llega a constituir los principios de la cultura magisterial, la cual puede advertirse como cadenas de significaciones construidas históricamente en donde los valores morales tradicionales se afianzaron a partir del modelo de familia nuclear, patriarcal y autoritaria impulsada durante la década de 1920 en lo que se define como el proceso de reconstrucción nacional. La familia nuclear de clase media sirvió como vínculo entre la tradición y la modernidad. (Cfr. Montiel, 2005).

MONSIVAIS, Carlos. (1988): "Notas sobre la cultura mexicana en el siglo XX", en Historia General de México 2. México, El Colegio de México, p. 33. 
$1^{\circ}$ ser educado es estar integrado a un nacionalismo cultural, $2^{\circ}$ estar integrado al proyecto nacional es tener acceso al progreso y, $3^{\circ}$ el progreso genera bienestar.

En estos tres argumentos es posible detectar lo que Anscombre y Ducrot , llaman redes argumentativas cuyo entramado forma un topoi, entendido como "creencias presentadas como comunes a cierta colectividad de la que al menos forman parten los interlocutores, quienes comparten la creencia, incluso antes del discurso en el que se emplea". En tal sentido los topoi conllevan un argumento lingüístico e ideológico, que operan bajo el supuesto de presuposiciones marcada por la experiencia propia de los hablantes.

En el caso del discurso de Rafael Ramírez encontramos tres topoi:

1. La educación integra al nacionalismo y con ello se tiene acceso al bienestar $y$ al progreso.

2. Ser objeto de control garantiza el éxito, por tanto, se justifica la institucionalización del control (supervisión).

3. Los cuerpos objeto del control, son alumnos, maestros y comunidad. Si éstos son controlados por la supervisión, progresarán.

\section{Acercamiento interpretativo a los textos formativos de profesores}

Rafael Ramírez, pedagogo mexicano de la posrevolución, es el primero en escribir en forma de reglamentos lo que debe ser el control y la dirección escolar, en esos textos también recoge parte de sus experiencias recopiladas de sus itinerarios de las escuelas rurales norteamericanas y del país. De ello desprende prescripciones para ser aplicadas a las escuelas rurales. Una idea constante en su texto es que el radio de acción de la educación debe ser social y abarcar aspectos económicos, higiénicos, de salud, nutrición, desarrollo cultural y adiestramiento comunitario en el uso de técnicas para la sobrevivencia, que permitan mejorar los estándares de la escuela y el progreso de la comunidad.

${ }^{15}$ ASCOMBRE, Jean Claude y Ducrot. (1994): La argumentación en la lengua. Madrid, Gredos, p. 122.

${ }^{16}$ Aunque el texto fue analizado de manera general y macroestructural, de acuerdo a Van Dijk, para el análisis textual sólo utilizaré tres capítulos: Cap. II: Breve análisis de la vida rural mexicana y magnitud y complejidad de su problema educativo. Cap. XVIII, La asistencia escolary la puntualidad. Cap. XXIV, Mejoramiento de la educación rural mediante la supervisión. Lo anterior por cuestión de delimitación y espacio, aunque en momentos recurriré a mostrar evidencias de otros capítulos como el XIX, La asociación de padres de familia. 
Se habla de conceptos como eficiencia, eficacia y éxito, pruebas, estandarización y gradualidad en el avance; también se muestran escalas para calificar las escuelas en buenas, regulares y malas. Pero sobre todo se justifica la retícula de la acción educativa en el espacio doméstico y en el cuerpo dócil de los educandos, el control, el panóptico, la vigilancia y el sometimiento, visto desde la perspectiva de Michel Foucault, bajo la tesis de que el sujeto que ejerce el control (supervisor) debe tener un grado mayor en la jerarquía organizacional no sólo sobre la comunidad, sino sobre el propio maestro. Su autoridad está en ser el más preparado y el más apto para elevar a la comunidad "del plano inferior de vida que actualmente ocupan, al plano inmediatamente superior y de allí al más alto", ${ }_{18}^{17}$. Lo que implica la díada entre el Saber y el Poder ${ }^{18}$.

Ramírez, parte de que el escenario rural es hostil, pobre, marginal y heterogéneo. Incluso llega a concebir la heterogeneidad étnica como uno de los problemas graves que se tendrá que resolver con educación indígena y no sólo con castellanización ${ }^{19}$. Considera que la gran masa de indios y campesinos deben integrarse al progreso a través de una cruzada nacionalista emprendida por la educación rural. De ahí que la figura y el ámbito de actuación, tanto del maestro-director y supervisor, no sólo se justifiquen sino además se comiencen a tejer en lo que aquí llamaré la trivialización del poder, visto no como un puesto o tarea burocrática sino como sinónimo de servicio social y de entrega al otro, a partir del vínculo de un imaginario fundamental: la familia y la vida doméstica ${ }^{20}$, que con el tiempo se traduce en el mandato. Estos dos imaginarios se instituyen en la perspectiva de la construcción del nacionalismo posrevolucionario, necesario para constituir una identidad ${ }^{21}$.

${ }^{17}$ RAMÍREZ, R. (1944): Organización y administración de Escuelas rurales. México D. F., SEP, Instituto Federal de Capacitación del Magisterio, Biblioteca Pedagógica de Perfeccionamiento Profesional, p. 77.

${ }^{8}$ El poder en tanto una legitimación de dominios de producción y acción, así el poder este en tanto se inserta como un saber desde una verdad legitimada y que justifica ciertas acciones reconocidas, visibles en un determinado dominio. Por tanto podersaber forman una diada recíproca, en tanto no se tiene poder sin saber y no se posee el saber sin poder.

${ }^{19}$ Ibídem., p. 77.

${ }^{20}$ La familia y la vida doméstica, imágenes tomadas de la clase media urbana, de la familia nuclear, bajo el precepto católico cristiano que exalta los valores familiares, en contraposición con los valores individuales de la versión protestante del cristianismo. 
El documento, muestra la visión instituida del ser maestro, las disposiciones básicas del oficio y permite también analizar desde el recurso de generalización la perspectiva hegemónica de los problemas de la educación de ese entonces. Por otra parte, a través de estrategias de ejemplificación se prescribe cómo hacer las cosas en una escuela y a la vez señalar casos de escuelas ejemplares dignas de ser imitadas.

\section{La estructura del reglamento}

Hay un sentido didáctico y por tanto práctico de sus 28 lecciones, a través de una retórica cargada de ejemplos y recursos morales: si haces esto, por lo tanto pasará aquello; imperativos categóricos: deber fundado en premisas universales; así como imperativos hipotéticos: una acción, desemboca en una consecuencia práctica ${ }^{22}$.

$\mathrm{Al}$ ser un documento con lecciones escritas en forma de manual práctico, puede ser analizado por lecciones fragmentadas, ya que el acceso a cada lección no exige de elementos previos. La forma de cada lección está estructurada en una introducción, una serie de lineamientos a ser seguidos y una conclusión. Su contenido incluye un discurso de legitimación de la función social de la escuela, de su necesario control y de la justificación de una existencia de jerarquías entre los maestros, la clasificación de maestros en buenos, malos y regulares, la necesidad de un supervisor, el más capaz y preparado, cuya figura motivaría la superación de los maestros, malos de por sí, y los llevaría a su mejora.

${ }^{21}$ Desde mi perspectiva hay dos momentos fundamentales en la conformación de la identidad y el espíritu nacional, el primero en el siglo XIX y el segundo en el siglo XX. Con respecto al primero, puede decirse que México experimentó un proceso de invención, ya que en 1821 al derrocarse el gobierno español quedó un vacío que tardó tiempo en llenarse, con Juárez podemos ver el advenimiento de un Estado, un tanto definido; pero además los intentos de literatos, filósofos, políticos por crear una literatura y una cultura nacional; un ejemplo fue la primera asociación literaria mexicana fundada en 1836, la Academia de San Juan de Letrán; otro caso fue el surgimiento de la primer novela americana: "Elperiquillo sarmiento" que incorporaba el habla popular; con respecto a las artes plásticas, la pintura de José Ma. Velasco; en la ciencia, los ensayos científicos de Luis de la Rosa; en la filosofía, el surgimiento de la filosofía latinoamericana con su pregunta sobre el ser auténtico de los latinoamericanos. Finalmente, en la pedagogía: el pensar en una educación para los mexicanos, con el proyecto liberal. El segundo momento tuvo su detonante con la revolución, con el resurgimiento de lo mexicano, el muralismo, la literatura posrevolucionaria, el cine, la filosofía de lo mexicano y el nacionalismo posrevolucionario.

El imperativo categórico se funda en un deber ser normativo: " $\mathrm{X}$ " realiza " $\mathrm{Z}$ " porque " $Z$ " es un deber; el imperativo hipotético se funda en un consecuencialismo de la acción: si hago $Z$ obtendré un beneficio $Y$, el prescriptivismo es un elemento que al ser considerado bueno para algunos se intenta convertir en norma que se generaliza en el sentido en que se convierte en prescripción para otros: $\mathrm{Si}$ " $\mathrm{X}$ " es bueno para "Y", por tanto "X" debe ser bueno para todos. Conclusión: Todos deben practicar X. 
En cuanto a la estructura argumentativa de los capítulos, se advierten dos tipos: uno deductivo que parte de principios generales y abstractos, como el capítulo 3 donde el punto detonador es un principio no cuestionado en el propio discurso: "Es indiscutible que la escuela educa, pero también es indudable que el hogar, la comunidad, la iglesia, la calle...ejercen sobre la gente influjos educadores tan profundos y a veces definitivos" ". La otra estructura argumentativa es inductiva inicia dando una serie de datos particulares, referencias o experiencias concretas, para ir justificando principios expresados en frases categóricas y contundentes, por ejemplo el capítulo 19 referido a "La Asociación de Padres y Madres de Familia", que inicia con un relato de su visita a una escuela ubicada en una comunidad rural "cerca del volcán de la Malinche" en Tlaxcala, y de las particularidades del trabajo comunitario del profesor Teja. De esta experiencia, Ramírez desprende una serie de recomendaciones puntuales y concluye diciendo:

Han pasado ya desde entonces muchos días, y hoy que hago recuerdos de ese viaje de estudio mío, no quiero concluir el relato sin recomendar a todos los maestros rurales del país la conveniencia de unir a toda la gente adulta del poblado en que trabajan, en una asociación más o menos parecida a la organizada por el profesor Teja .

En general, podemos señalar que este material está destinado a normalizar la organización escolar, es un manual y a la vez un texto formativo, por tanto contiene un doble propósito decir cómo hacer y qué hacer (técnicas, métodos y estrategias), a la vez de ser un dispositivo de formación (muestra valores, prescribe, señala, define el deber ser docente).

Expresa cuestiones normativas de manera:

...marcadamente práctica...listas para ser aprovechadas por los maestros en sus tareas escolares diarias. Por lo tanto, aunque sobre cada uno de los puntos del programa presentaremos en forma vigorosa y clara el cuerpo de la doctrina más válido, no hemos de detenernos mucho en eso, pues la mayorparte de nuestra atención se aplicará a desprender de esa doctrina las deducciones prácticas que servirán a los educadores, a manera de herramientas, para realizar la obra que la sociedad les tiene encomendada.

${ }^{23}$ RAMÍREZ, R. (1944): Organización y administración de Escuelas rurales. México, D. F. SEP, Instituto Federal de Capacitación del Magisterio, Biblioteca Pedagógica de Perfeccionamiento Profesional, p.113.

${ }_{25}^{24}$ RAMÍREZ, R. (1944): óp., cit, p.113.

${ }^{25}$ RAMÍREZ, R. (1944): óp., cit, p.113. Los puntos suspensivos son míos. 
Los veintiocho capítulos son nombrados lecciones:

...los primeros persiguen el propósito de dar a los maestros en servicio una idea global del problema educativo del país, en su conjunto". "Las lecciones posteriores van todas ellas encaminadas hacia la mira de capacitar plenamente a los estudiantes normalistas y a los maestros rurales en pleno trabajo, para organizar bien el servicio educativo que van a tener o tienen ya bajo su cuidado $y$ dirección, no sólo desde el punto meramente escolar, sino social.

Inicia con un diagnóstico de los grandes problemas de la educación rural $^{27}$ donde una vez que expone con datos, cifras, ejemplos y comparaciones de la gravedad del problema, concluye con una frase contundente y categórica sobre el deber ser de la escuela rural, esto es su misión, revestida de consejas morales y reglas prácticas para la conducción de las escuelas. En momentos resalta la estructura normativa, con actos ilocutivos propios de los reglamentos, conteniendo expresiones declarativas como: "Es cuestión de organizar la escuela y de conducirla rectamente..." Otras son imperativas: "La educación higiénica debe constituir uno de los capitulos de la acción social que todo maestro está obligado a conducir, cualquiera que sea la comunidad en que trabaje" como se puede apreciar en el siguiente fragmento:

Dentro de la escuela, y con los niños, los maestros pueden hacer mucho a favor de una mejor puntualidad y de una mejor

\footnotetext{
${ }_{27}^{26}$ Ibídem., p. 120.

${ }^{27}$ El segundo capítulo o lección es "Breve análisis de la vida Rural Mexicana y magnitud y complejidad de su problema educativo" donde resume y analiza brevemente en nueve puntos la problemática: 1. México es un país esencialmente rural. 2. Los sectores más afectados son: la salud, la alimentación, la ignorancia, la pobreza: "La educación rural mexicana debe ser en buena parte una educación higiénica" p.14; 3. "La pobreza de la vida doméstica. 4. La falta de tierras, el despojo de éstas y los salarios de hambre en la población que alquila su trabajo.'La educación ha de tener una clara y fuerte orientación económica" 5. La vida campesina es monótona y aburrida, la gente campesina carece de contactos e intercambio cultural: "La educación debe promover la vida social y recreativa" p.16; 6 . Dado que México es un país de analfabetas: "La educación debe consistir en eliminar totalmente el analfabetismo" p. 18; 7. La estructura racial de la nación es heterogénea. "Esa heterogeneidad étnica de la población tiene que traducirse forzosamente en un problema no ya de simple castellanización, sino de educación propiamente dicha, en un problema de educación indígena, para usar la exacta y verdadera expresión". 8. hay diversidad geográfica, núcleos de población diseminados en su territorio, fanatismo, prejuicios, y supersticiones arraigados en la población rural del país. 9. No existen agencias culturales de ninguna especie en las áreas campesinas, fuera de la modesta escuela rural. p. 20. Se llama acto ilocutivo a la expresión que define una intencionalidad, partiendo de la tesis de Austin en el sentido de que el lenguaje no solo refiere algo, sino también expresa órdenes, deseos o permisiones Cfr. Austin (1955) Cómo hacer cosas con palabras en edición electrónica www.filosofia.cl/ Escuela de Filosofía Universidad ARCIS
} 
asistencia. Una campaña permanente de puntualidady de asistencia bien organizada y sabiamente conducida entre los alumnos, que ponga en competencia a los diversos grupos de la escuela, que señale premios a los grupos vencedores puede ser muy eficaz. Aparejado con esta campaña debe ir el estricto control de la asistencia y de la puntualidad diarias de los niños, a fin de llamar o visitar a los padres de los alumnos impuntuales o faltistas y solicitar su cooperación. Finalmente, cuando todas las cosas que se ban dicho fallen, todavía queda el recurso de pasar semanariamente a la autoridad competente del lugar la lista de los alumnos faltistas e impuntuales, para que amoneste a los padres renuentes o les imponga las sanciones reglamentarias en caso de reincidencia habitual.

De alguna manera, la posición coercitiva expresada en el "Debe ir el estricto control' va acompañada de una serie de acciones previas como son el ejemplo, el premio, el trabajo, la iniciativa, la invitación a la comunidad y la generosidad, todos estos son medios eficaces para lograr el fin: asistir, como condición, a ser educados en la escuela. Si esto no se cumple, entonces se recurre a la sanción máxima: amoneste a los padres renuentes o les imponga las sanciones reglamentarias en caso de reincidencia habitual ${ }^{30}$. Pero antes se tienen que buscar estrategias para cambiar esa "actitud mental" como lo podemos advertir en el siguiente texto:

La cuestión de la impuntualidad y de la irregular asistencia de los niños a la escuela no es un problema insoluble. Ya al enumerar y comentar las causas del fenómeno hemos ido apuntando los remedios. De manera general, pudiéramos decir que todos ellos se reducen a dos: uno el de educar a la comunidad tomada por entero mediante una campaña ilustradora a favor de los beneficios que la escuela proporciona a las generaciones del porvenir; otro, el de acondicionar y conducir la escuela satisfactoriamente para obtener de ella el mejor provecho educativo.

La orientación de la acción de los sujetos parece incluir sanciones normalizadoras que junto con la inspección jerárquica constituyen lo que Foucault denomina instrumentos de poder disciplinario ${ }^{32}$. En este tipo de sanción normalizadora están implícitos dos actores, que se configuran en las dualidades siguientes: el educado - el no educado; el culto - el ignorante, la autoridad- el sometido.

\footnotetext{
${ }_{30}^{29}$ Ibídem., p. 120.

${ }_{31}^{30}$ Ibídem., p.138.

${ }_{32}^{31}$ Ibídem., p.138.

${ }^{32}$ FOUCAULT, M. (1976): Vigilary castigar, Nacimiento de la prisión. México, Siglo XXI, p. 133.
} 
Estas posiciones duales serán el recurso estratégico que permea la totalidad de la obra y constituye la estructura semántica que da lugar a metáforas que proceden como juego de oposiciones en la justificación de un modelo: la educación ante el grave problema de la ignorancia y la pobreza. Lo que se expone a continuación es el análisis y la semantización de esas dualidades.

\section{La semantización de las dualidades en el texto}

De acuerdo al texto existe una sola y grave enfermedad social: La pobreza-ignorancia. La cual posee muchos síntomas igualmente dañinos e indeseables: la insalubridad, la enfermedad, la explotación, el desconocimiento de los derechos y las responsabilidades, la indiferencia, la codicia, etc.

Curiosamente, los males que acompañan la ignorancia no son sólo de tipo material, sino espiritual, uno de éstos genera el otro, o bien dimana del otro. En tal sentido Ramírez pone en un mismo punto la pobreza y la ignorancia:

Lapobreza de la gente puede dimanar de muchas circunstancias, como son: La carencia de tierras de cultivo, desinterés o descuido de la crianza de animales domésticos, empleo de instrumentos primitivos de labranza, rutina y métodos atrasados de trabajo, ausencia de iniciativa para aprovechar industrial o comercialmente los recursos naturales de la comarca, ignorancia de los métodos de organización para encontrar mercado de los productos rurales; falta de carreteras y caminos vecinales $y_{33}$ de medios de transporte que faciliten la salida a los productos etc.

Este segmento muestra que la pobreza dimana de diversas circunstancias que se pueden agrupar en dos niveles: objetivos y subjetivos. Siendo más numerosas las circunstancias subjetivas que las objetivas, se deriva que la pobreza es en mayor grado originada por actitudes subjetivas. Este recurso argumentativo le permite a Ramírez justificar el papel de la educación como un remedio o cura para el mal, puesto que si éste está colocado en la subjetividad y depende de los sujetos, entonces la educación podrá vencer al enemigo de la pobreza. Como se ilustra en el cuadro 1:

\footnotetext{
${ }^{33}$ Ibídem., p. 76.
} 
Cuadro 1: Condiciones objetivas y subjetivas de la pobreza

\begin{tabular}{|c|c|}
\hline Condiciones objetivas & Condiciones subjetivas \\
\hline Carencia de tierras de cultivo & $\begin{array}{l}\text { Desinterés o descuido de la crianza de } \\
\text { animales }\end{array}$ \\
\hline \multirow[t]{4}{*}{ Falta de carreteras y caminos vecinales } & $\begin{array}{l}\text { Ausencia de iniciativa para aprovechar } \\
\text { recursos }\end{array}$ \\
\hline & Empleo de instrumentos primitivos \\
\hline & Rutina y métodos atrasados \\
\hline & Ignorancia de los métodos de organización \\
\hline
\end{tabular}

Fuente: análisis del libro por la autora.

En tal sentido es posible la propuesta de que "educar a la comunidad", educar implica una acción de remedio para curar y combatir un mal:

Todas estas circunstancias ventajosas pueden ser combatidas con una educación de vigorosa tendencia económica difundida persistentemente en el seno de la comunidad mediante una acción social bien planeada, desarrollada por los maestros.

Aquí vemos un juego de metáforas, utilizadas en el sentido de poner en juego dos figuras: la cura o remedio ofrecido por la educación frente a la enfermedad o el mal que genera la pobreza y la ignorancia y que evita que las comunidades rurales vean como un bien social a la educación. A continuación ilustro esta idea en el cuadro 2.

Cuadro 2: Metáforas opuestas

Enfermedad

Pobreza del vecindario

Pésimas condiciones higiénicas

Impropia organización del trabajo doméstico

Afán de explotación del trabajo infantil "Vigorosa cruzada hasta acabar con esa práctica"

Desconocimiento de la obligación legal "El maestro debe desarrollar un plan de por parte de los padres para procurar la ilustración hasta lograr que en el poblado se educación primaria a sus hijos. constituya una opinión pública sobre la ley"

La indiferencia de los padres, como "Educar a la comunidad"

resultado de la ignorancia.

La mala organización de la escuela

Un maestro incompetente, vicioso,

desinteresado, apático

Fuente: análisis del libro por la autora.

${ }^{34}$ Ibídem. p. 76. 
En suma, la pobreza y la ignorancia están puestas en el mismo nivel, dimanan y a la vez originan situaciones subjetivas: actitudes, perspectivas y valores que habrá que combatir ${ }^{36}$ el maestro (el cual es un soldado y/o apóstol, en el sentido de la lucha espiritual y la búsqueda de la conversión del otro) desde su trinchera (La escuela rural, la educación, su enseñanza, su plan de ilustración) tendrá que combatir y curar espiritualmente a la comunidad: es el héroe que rescata a la comunidad de su destino oscuro. Por eso la justificación del sacrificio, la vocación y la entrega sin mayor mérito que la satisfacción del servicio:

...en suma, un maestro sin vocación, que solamente por azar ocupa un cargo de tanta responsabilidad, nunca podrá ver las aulas llenas de niños, tampoco llegará a saborear la deliciosa alegría de ver concurrir, a los pocos que asisten, puntualmente y con regularidad.

El plan de ilustración al que continuamente alude Ramírez, tiene que ir dirigido al vecindario o comunidad, la palabra ilustración alude a iluminar, dar luz donde hay tinieblas; imagen que asocio a la tríada platónica de: la verdad, la bondad y la belleza, y particularmente ligo al recurrente manejo de los adjetivos con los que Ramírez elogia el proyecto de educar a la comunidad: satisfacción, avance, éxito, buena escuela, deleite, belleza, progreso, buen sabor, etc. Todos ellos asociados con la idea de que la educación produce no sólo bien social o progreso, sino deleite al sentir que el maestro cumple con el mandato.

Además, en el plan de ilustración se muestra al maestro como el ejemplo del deber ser: el maestro debe crear una actitud mental:

...la regularidad en la asistencia escolar y la puntualidad son dos actitudes mentales que los maestros deben crear tanto en los alumnos como en sus padres. Sin esas actitudes mentales, la irregular asistencia y la falta de puntualidad serán dos cosas permanentes que estorbarán al desenvolvimiento de la escuela, el progreso de los alumnos y el avance de toda la comunidad.

\footnotetext{
${ }^{35}$ En este sentido Ramírez es confuso: en momentos señala que la pobreza es causada por la ignorancia, en otros que la ignorancia y la pobreza están juntas: nacen y crecen juntas; en otros momentos la ignorancia parece provenir de la pobreza.

En tal sentido, habrá que recordar que estos dos adjetivos: La ignorancia y la pobreza habían constituido el binomio de nuestros más grandes enemigos, el de los maestros, como lo había señalado, José Vasconcelos: "La pobreza y la ignorancia son nuestros peores enemigos, y a nosotros nos toca resolver el problema de la ignorancia" (Discurso de toma de posesión del cargo de rector de la Universidad Nacional Autónoma de México, 1920) tomado de Monsiváis, 1988.

${ }_{38}$ Ibídem., p. 76.

Ibídem., p. 76.
} 
En otros momentos del discurso, reitera la "actitud mental" de manera semejante a las gafas que impiden ver la luz e ilustrar al espíritu. En ello persiste nuevamente la concepción platónico-cristiana de la luz. como la verdad, propia del conocimiento, la cual es considerada un bien superior. Este recurso retórico es un elemento estratégico el cual concibe que la humanidad deberá estar iluminada por la verdad y la guía de un espíritu que libra del enemigo o vence a la ignorancia y justifica una educación a la comunidad, un control del cuerpo basado en el discurso de la higiene, del progreso y del avance. Esto legitima una educación cuya acción se orienta a incidir en el ámbito doméstico, privado, familiar y en el sentido de la disciplina, alimentación, puntualidad, asistencia, manejo de alimentos, técnicas, economía, organización, etc.

La vida doméstica y social en las áreas rurales puede decirse que se desenvuelve toda entera haciendo caso omiso de las reglas más sencillas de la bigiene y de los principios sanitarios más elementales. Por otra parte, en el campo no hay médicos ni enfermeras; tampoco hay boticas ni hospitales ni casas de maternidad; en suma, no hay agencias bigiénicas ni médicas, ni sanitarias de ninguna especie. Lo que abunda en el México rural son los hechiceros y curanderos que ocasionan quizás más muertes que las enfermedades mismas ${ }^{39}$.

Para Ramírez la educación sería un bien mayor porque vencería muchos males sociales, uno de ellos el problema de la salud, a través de dispositivos como la higiene, el control de alimentos, la dieta, el manejo de técnicas para la producción de alimentos y cultivos en el campo, etc. También en esta posición se puede apreciar una nueva relación antitética entre el "saber de la comunidad" y el "saber de la escuela". La escuela es la institución que deberá arremeter contra el saber experiencial, propio de la ignorancia, el fanatismo, la superstición, situaciones que dañan a las comunidades hundiéndolas en su propio atraso. La educación combatirá estos males; esta noción de combate, propia de la cruzada espiritual guerra contra el fanatismo, acentúa la figura del apóstol, figura necesaria en la consolidación de un imaginario docente que guía sus acciones hacia una ruta: la misión de transformar las comunidades en escenarios de progreso, como se muestra en el cuadro 3.

\footnotetext{
${ }^{39}$ RAMÍREZ, R. (1938): Curso de Educación Rural. México D. F., Citado por Ramírez en Organización y administración de Escuelas rurales. (1944). México, D. F., SEP, Instituto Federal de Capacitación del Magisterio, Biblioteca Pedagógica de Perfeccionamiento Profesional.
} 
Cuadro 3 Antitesis entre saber escolar y saber experiencial

Saber experiencial Saber escolar

Es producto de la ignorancia, el fanatismo y Es el saber científico.

la superstición.

Es propio de los nativos: hechiceros y curan- Es propio de los médicos, enfermederos ras, científicos, maestros.

Se adquiere por vía de la experiencia práctica. Se adquiere en espacios institucionales y formales: escuela y universidad

Es dañino, causa más daño que la propia en- Es benéfico, sólo con la ciencia se fermedad logran superar las condiciones de precariedad

Reproduce la ignorancia Conduce al bienestar social

Fuente: análisis del libro por la autora.

En este cuadro se puede ver la relación, nuevamente antitética o maniquea, que expresa la distancia entre el conocimiento de la comunidad y que la escuela en su misión tendría que derribar para imponer su ciencia a través del saber adquirido, sí y sólo sí, en su institucionalidad.

Este conjunto de antítesis, son interesantes ya que Ramírez las utiliza de manera estratégica para convencer sobre los frutos de la educación y los bienes que acarrearía su acción social. En un punto donde se juntan los planos: ignorancia y la ciencia- progreso y retroceso, ubica al maestro indiferente, igualmente dañino a la comunidad, por su falta de su compromiso al cambio. En el plano del progreso - ascenso, está la ciencia y la mejora continua propia de las buenas escuelas que cuentan con una supervisión que garantiza no sólo las condiciones materiales sino la capacitación constante de los docentes. En el cuadro 4 podemos apreciarlo.

Cuadro 4: La semantización de las relaciones antitéticas

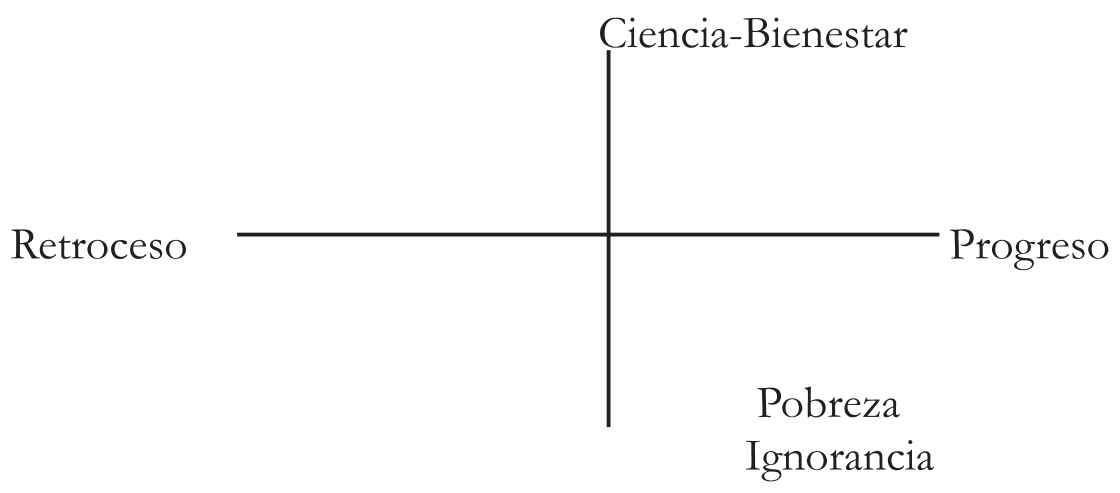


Ramírez persiste en que los recursos estratégicos para el éxito de la tarea del maestro son: seducir, convencer, atraer, ponerse en el lugar del otro, adaptarse, partir de las necesidades del vecindario. Lo que se puede ver en el ejemplo del profesor Teja, es que la virtud subjetiva del maestro conduce al éxito entre los pobladores de la comarca: la manera como les habla, como se dirige a ellos, como elige y convoca a la población, etc. De ahí que seducción y atracción se entremezclan para ponderar que el poder y el control no sólo se justifican, sino además se eufemizan al estar vinculados con el beneficio social, la entrega, la empatía y la necesidad. $\mathrm{El}$ poder y el control son por el amor , por la caridad, por el deber, por lo imprescindible, nociones que empatan con un interdiscurso ${ }^{41}$, el de Vasconcelos, vigente en ese tiempo y que Ramírez vivifica:

Ligar el esfuerzo misionero católico, que engendró nuestra nacionalidad con un proselitismo regenerador, que sin perjuicio de especializarse en los aspectos técnicos de la cultura moderna, lograse frutos del espiritu tan fecundos como los antiguos, cuya raiz es el amor del semejante.

\section{La trivialización del poder}

Hay un lenguaje de denegación que opera como núcleo de sentido al mostrar las tácticas justificatorias y de trivialización del poder, que permiten tanto a profesores como supervisores asumir su papel de control y sujeción. En tal sentido Ramírez inicia con una frase que justifica el papel del supervisor:

Todos los países que desean mantener vivos sus sistemas escolares y aptos para prosperar aumentando cada día su actual eficiencia, han creado una institución especialmente dedicada a cuidar de que la vitalidad no se adormezca y se mantenga no solo despierta, sino siempre activa. Esa institución es la supervisión escolar.

\footnotetext{
${ }^{40}$ En este sentido podemos señalar que el primero que utiliza la estrategia de eufemización del poder es Pablo de Tarso, v.gr. cuando justifica la autoridad del hombre sobre la mujer, lo hace a través de la metáfora de la fragilidad y el cuidado sumo que merece el objeto frágil: el hombre debe ver a la mujer como el vaso más frágil. En momentos la estrategia para la eufemización es la metáfora por oposición Fuerza-fragilidad, en otros la analogía: "así como Cristo es la cabeza de la iglesia, el hombre es la cabeza de la mujer", o bien por metonimia: Cristo, el maestro...los cristianos, su imagen. Con este recurso se suaviza la noción de poder y hasta se reconoce discursivamente como un recurso bueno y necesario.

Interdiscurso se entiende como una serie de elementos discursivos de la época que permitieron la concreción y aceptación de modelos, referentes, imágenes o ideas. Todas en su conjunto se ligan a un imaginario social.

${ }_{43}^{42}$ VASCONCELOS. (1924): Monsiváis, óp., cit. 1988:1027

${ }^{43}$ RAMÍREZ. (1944): óp., cit, p. 45.
} 
La estructura argumentativa de esta frase es la implicación material: si a toda "X" corresponde " $Y$ ". Existe "X", conclusión, hay "Y". Si existen buenas escuelas por tanto hay control. Existe una buena escuela, conclusión, hay control. Del argumento de implicación material, se infiere que la institucionalización del control es la supervisión escolar, condición de una buena escuela.

Nuevamente la metáfora de una buena escuela es representada con la imagen de un ser vivo, lo cual se puede inferir de términos como: vitalidad que no se adormezca, se mantenga despierta, siempre activa. El ser vivo (la escuela) debe estar despierto y activo (síntoma de buena salud) y es la supervisión la institución responsable de cuidar la salud.

Me detendré brevemente a analizar las implicaciones de esta recurrente metáfora.

El cuidar la salud, el mantener vigoroso un cuerpo para que esté despierto y crezca sano, es propio de quien ofrece un servicio de atención, de manutención y de enfermería, propio del padre o madre que cuida su prole, la atiende, la alimenta y ve por su bienestar. Aquí resaltan cualidades centradas más en el ámbito doméstico: ser un buen padre o una buena cuidadora: paternidad y maternidad ${ }^{44}$.

El discurso señala:

El campo en el que opera la supervisión escolar es de un radio de acción muy amplio. No solamente tiene que ver con las escuelas, cuya eficiencia está obligada a aumentar constantemente; los maestros que las sirven caen asimismo dentro de su jurisdicción, pues el crecimiento cultural y profesional continuado y permanente de tales educadores, es una de las tareas fundamentales de la supervisión.

\footnotetext{
${ }^{44}$ En tal sentido, sostengo que los valores tradicionales no abandonaron el imaginario social de la época sino que vinieron a jugar un papel fundamental en el proyecto de unificación del país, "los años veinte finalizaron con un entendimiento entre la iglesia católica y el Estado llegando a una convivencia pacífica, después de todo sus metas en cuanto al control de las conciencias no eran tan opuestas y los valores del catolicismo empataban bien con el 'nuevo' modelo de desarrollo" Muñiz, 2002, p. 87. La familia y la escuela oficial fueron reconocidas por el Estado como ámbitos de socialización que le permitirían impulsar desde la vida cotidiana su proyecto nacionalista.

RAMÍREZ, Rafael. (1968): Obras Completas VII. Gobierno del Estado de Veracruz. México. SEP, p. 188.
} 
Como podemos ver, Ramírez busca especializar la labor de los supervisores rurales. La supervisión era una institución que debía no sólo aumentar la eficiencia de las escuelas, sino también hacerse cargo del crecimiento cultural y profesional continuado de los maestros. Ramírez, a través de actos ilocutivos plantea imperativos sobre el "deber ser" del supervisor, entre éstos destacan una actitud de colaboración y servicio en donde el supervisor "debe pensar que dentro del grupo no es propiamente un jefe", con un proceder democrático en donde el supervisor aprovecha la cooperación de todos los trabajadores y en donde la dirección se confiere al supervisor no en virtud de un nombramiento oficial sino derivado del acuerdo tácito de los trabajadores ${ }^{46}$. Además, Ramírez afirma que:

La educación de las masas no constituye, una empresa de carácter económico, sino una empresa pública en la que todos los ciudadanos del país están obligados a cooperar del mejor modo; insano, porque en esta empresa pública no puede hacerse la distinción entre trabajadores y patrón, pues todos -maestros y supervisores- son cooperarios .

Con la negación del carácter económico de la relación laboral, Ramírez utiliza una estrategia de trivialización de dicha relación. La coloca en el ámbito doméstico, en el lugar del desinterés económico, de la igualdad y el servicio, valores ligados a la doctrina cristiana, así establece formas de relación que, siguiendo a Foucault, pueden entenderse como el despliegue de una técnica de "poder pastoral" en donde se combinan individualización y procedimientos totalizadores. Por otra parte concibe que este papel exige una especialización de la tarea del control y una jerarquía mayor:

...elpapel del supervisor es demasiado serio para que cualquier gente pueda representarlo. Los maestros mismos, de quienes a causa de su profesión podríamos conjurar que serían capaces de hacerlo, para desempeñarlo satisfactoriamente necesitan hacer estudios adicionales especializados; sin contar las capacidades de organización y administración y el temperamento de líder social que los aspirantes deben poseer.

\footnotetext{
${ }^{46}$ Puede parecer una aparente contradicción el hecho de que aquí señale que el supervisor no es un jefe, y en otro momento considere que tendrá que ser el más preparado y con mayor liderazgo. Sin embargo esta aparente contradicción se comprende cuando Ramírez, señala que su posición se justifica precisamente por la necesidad de una figura que motive el progreso y no por un bien material o de reconocimiento personal. ${ }_{48}^{47}$ RAMÍREZ, Rafael. (1968):óp., cit, p.16.

${ }^{48}$ FOUCAULT, Michel. (1986): Por qué hay que estudiar el poder: La cuestión del sujeto. En WV. Mills. Materiales de sociología crítica Madrid, La piqueta, pp. 25-36.

RAMÍREZ. (1944): óp., cit, p. 136.
} 
Se podría decir que Ramírez construye un proyecto institucional de fundación con relación a la supervisión en tanto que señala los fines, las metas y propósitos que ésta desea alcanzar y que con el tiempo llegó a constituirse en un "mandato" heredado por supervisoras y supervisores, quienes despliegan formas de acción que atienden a las premisas de dicho mandato, por lo que se trivializa la relación laboral a través del despliegue de un poder pastoral ${ }^{50}$.

Por otra parte, es interesante que Ramírez recurra a términos como el deseo, la obligación, el estimular, el conducir, la culpa, la satisfacción; términos que aluden nuevamente el carácter subjetivo e intrínseco de la función, su trivialización: por el deseo se mueve la voluntad, por el deseo se prospera... la recompensa por la labor cumplida es también subjetiva, el incumplir con la misión genera culpa, ésta es propia del cristiano que se inclinó hacia el mal, pudiendo elegir el bien:

A ellos corresponde la tarea de transformar poco a poco las escuelas malas en medianas, las medianas en buenas y las buenas en sobresalientes, tarea hermosa en verdad que de realizarse llenaría de satisfacción al supervisor más exigente consigo mismo.

La culpa de ello (la inasistencia e impuntualidad) pueden tenerla los propios niños, pero por regla general los culpables son los padres, y a menudo la responsabilidad de estas deficiencias corresponde por entero a los maestros. Graduamos la culpabilidad en esta forma para no lastimar la susceptibilidad de los educadores .

Ramírez, primero señala que la culpa mayor es de los profesores, pero enseguida trivializa esta posición señalando Graduamos la culpabilidad en esta forma para no lastimar la susceptibilidad de los educadores, aquí subyace el supuesto de que el discurso, de por sí, podría lastimar a alguien. Esta suposición de plantear la vulnerabilidad por el sólo hecho de recordarle a alguien el deber incumplido, es un señalamiento del honor y de la conciencia moral ante la promesa agraviada.

El presente texto, escrito en forma de manual, está vertebrado y atravesado por el discurso educativo oficial, donde también confluían sentidos moralizantes y humanizadores, ya que los valores tradicionales no abandonaron el imaginario social de la época sino que vinieron a

\footnotetext{
${ }_{51}^{50}$ FOUCAULT, M. (1986): óp., cit, p. 26.

${ }^{51}$ RAMÍREZ. (1944): óp., cit, p. 89.
} 
jugar un papel fundamental en el proyecto de unificación del país, "los años veinte finalizaron con un entendimiento entre la iglesia católica y el Estado llegando a una convivencia pacífica, después de todo sus metas en cuanto al control de las conciencias no eran tan opuestas y los valores del catolicismo empataban bien con el 'nuevo' modelo de desarrollo",

\section{CONCLUSIÓN}

A través del análisis efectuado podemos ver que la familia y la escuela oficial fueron reconocidas por el Estado como ámbitos de socialización que le permitirían impulsar desde la vida cotidiana su proyecto nacionalista. Este texto permite entender desde su estructura, sus metáforas y sus estrategias discursivas, los imaginarios y representaciones que habrán de influir en la institucionalización de la escuela pública mexicana. El discurso de la pobreza bajo la metáfora de la enfermedad habrá de ser determinante para justificar que los educadores son los médicos sociales de las comunidades, pudiendo influir sobre el cuerpo enfermo para erradicar de él su mal. Desde tal metaforización y analogía, la pobreza asociada a la ignorancia, eran concebidos como males sociales que se remedian con la educación; y, la consecuencia del radio de acción de la educación, fue la justificación de la aplicación del conocimiento a la realidad cotidiana de las comunidades, por tanto, los maestros fueron vistos como los encargados de curar el enemigo social de la pobreza.

Para poder entender esas filtraciones del discurso estructurante: familia-religión, el texto utiliza tres elementos fundamentales: la metaforización, entendida como estrategia eufemizante; la analogía como estrategia trivializante, y el imaginario instituido de la familia bajo el precepto católico de la unidad y el bien pastoral. No es posible asegurar que este imaginario persista, lo cierto es que en los discursos de los directivos la figura del apóstol laico fue un elemento constitutivo que configuró su práctica.

\footnotetext{
${ }^{52}$ MUÑIZ, Elsa. (2002): Cuerpo. Representación y poder, México en los albores de la reconstrucción
} nacional, 1920-1934. México, Universidad Autónoma Metropolitana, p.87. 


\section{REFERENCIAS}

ASCOMBRE, Jean Claude y DUCROT. (1994): La argumentación en la lengua. Madrid, Gredos.

FOUCAULT, Michel. (1976): Vigilar y castigar, Nacimiento de la prisión. México, Siglo XXI.

FOUCAULT, Michel. (1986): Por qué hay que estudiar el poder: La cuestión del sujeto, en Materiales de sociología crítica. WRIGHT Mills. Madrid, La piqueta.

FOUCAULT, Michel. (2001): Tecnologías del yo. Barcelona, Paidós-ICE-UAB.

LAKOFF, George y MARK, J. (1980): Las metáforas de la vida cotidiana. Madrid. España, Editorial cátedra.

MENESES. (2000): El saber educativo en un siglo de la educación en México. México, Ed. Siglo XXI.

MIÑANO GARCÍA, Max. (1945): La Educación Rural en México. México, SEP.

MONSIVAIS, Carlos. (1988): "Notas sobre la cultura mexicana en el siglo XX", en Historia General de México 2. México, El Colegio de México.

MONTIEL ESPIgNOSA, María Trinidad. (2005): La supervisión en el sistema de educación básica del Estado de Hidalgo: la enfemización del ejercicio del poder y su relación con el género, México, D. F. Tesis doctoral UPN.

MUÑIZ, Elsa. (2002): Cuerpo, representación y poder. México en los albores de la reconstrucción nacional, 1920-1934. Universidad Autónoma Metropolitana. México, Porrúa.

RAMÍREZ, Rafael. (1982): La escuela Rural Mexicana. SEP/80, México. FCE.

RAMÍREZ, Rafael. (1938): Curso de Educación Rural. México, D. F., Citado por Ramírez en Organización y administración de Escuelas rurales. (1944). México, D. F., SEP, Instituto Federal de Capacitación del Magisterio, Biblioteca Pedagógica de Perfeccionamiento Profesional.

RAMÍREZ, Rafael. (1944): Organización y administración de Escuelas rurales. México, D. F., SEP, Instituto Federal de Capacitación del Magisterio, Biblioteca Pedagógica de Perfeccionamiento Profesional.

RAMÍREZ, Rafael. (1968): Obras Completas VII. Gobierno del Estado de Veracru\%: México. SEP. 
SEARLE, John. (1980): Actos de habla. Madrid. España, Ed. Cátedra.

VAN DIJK, Teun. (2001): El discurso como interacción social. Barcelona, España, E. Gedisa.

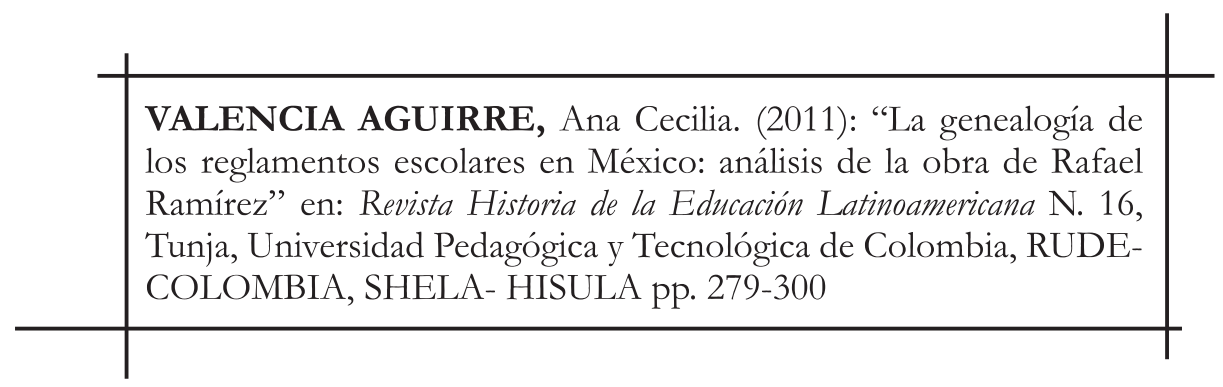

